\title{
Influence of Waste Fly Ash on the Rheological Properties of Fresh Cement Paste and the Following Electrical Performances and Mechanical Strengths of Hardened Specimens
}

\author{
Lili Cui ${ }^{1}$ and Hui Wang ${ }^{2, *}$ \\ 1 School of Energy and Civil Engineering, Harbin University of Commerce, Harbin 150006, China; \\ 101004@hrbcu.edu.cn \\ 2 School of Civil and Environmental Engineering, Ningbo University, Ningbo 315000, China \\ * Correspondence: wanghui4@nbu.edu.cn
}

Citation: Cui, L.; Wang, H. Influence of Waste Fly Ash on the Rheological Properties of Fresh Cement Paste and the Following Electrical Performances and Mechanical Strengths of Hardened Specimens. Coatings 2021, 11, 1558. https://doi.org/10.3390/ coatings11121558

Academic Editor: Paolo Castaldo

Received: 22 November 2021

Accepted: 16 December 2021

Published: 18 December 2021

Publisher's Note: MDPI stays neutral with regard to jurisdictional claims in published maps and institutional affiliations.

Copyright: (c) 2021 by the authors. Licensee MDPI, Basel, Switzerland. This article is an open access article distributed under the terms and conditions of the Creative Commons Attribution (CC BY) license (https:// creativecommons.org/licenses/by/ $4.0 /)$.

\begin{abstract}
Waste fly ash (WFA) is a kind of solid waste without reasonable disposition. The WFA with active substance can promote the cement hydration, therefore, WFA may enhance the mechanical strengths of cement-based materials. In this paper, the rheological properties (slump flow and plastic viscosity) of fresh cement paste with WFA ranging from $0 \%$ to $25 \%$ by mass ratio of cement were studied. The alternating current (AC) electrical resistance and direct current (DC) resistance time curves were determined. The AC impedance spectroscopy curves of the specimens cured for 1 day and 28 days were obtained. Finally, the mechanical strengths of hardened cement paste cured for 1 day, 3 days, 7 days, and 28 days were tested. The results showed that the slump flow was decreased and the plastic viscosity was increased by the addition of WFA and the increasing curing time. The AC electrical resistance increased in the form of the quadratic function with the cuing age. Meanwhile, the addition of WFA demonstrated an enhancing effect on the electrical conduction of cement paste. The variation rate of DC electrical resistance during the testing time increased with the increasing dosages of WFA and the curing age. The mechanical strengths increased with the addition of curing time and the content of WFA. The increasing rate of mechanical strengths increased with the addition of WFA $(0 \sim 15 \%)$ and decreased with curing time. However, when the dosage of WFA increased from $15 \%$ to $25 \%$, the increasing rate decreased.
\end{abstract}

Keywords: waste fly ash; fresh cement paste; AC electrical resistance; AC impedance spectroscopy; DC resistance time curves; mechanical strengths

\section{Introduction}

In recent years, environmentally friendly society has been the theme of the times. With the acceleration of urbanization, a large amount of domestic garbage is piled up in the city. The accumulated garbage will not only affect the appearance of the city but also pollute its water source. Therefore, the domestic waste needs to be disposed reasonably [1,2].

In the past, the domestic waste was usually incinerated into ash and then buried. The waste fly ash possesses a large amount of toxic and harmful substances polluting the soil and water sources after burring $[3,4]$. Nowadays, cement concrete is still the main building materials being widely used in the word. The production of concrete materials consumes a lot of energy and resources, thus resulting in a lot of harmful substances [5]. The application of waste fly ash in cement concrete can provide a good idea for the cyclic utilization of waste fly ash.

As reported in some journals, waste fly ash contains some active substances which are able to improve the hydration process of cement. Ren et al. [6] manufactured cement-based materials by replacing some cement with some waste fly ash. Researchers pointed out that the addition of waste fly ash could effectively improve the mechanical strengths with the dosages less than or equal to $40 \%[7,8]$. Moreover, the addition of waste fly ash could 
effectively improve the activity of cement matrix leading to increasing the mechanical properties of cement concrete [9]. The dissolution of toxic substances of cement concrete is the most important factor affecting the application in cement concrete. Some research findings reported that the dissolved toxic heavy metals from the reactive powder concrete comply with environmental protection requirements $[10,11]$. Therefore, waste fly ash is a kind of potential active additives which can be applied in the cement matrix.

The rheological properties of fresh cement concrete are of great significance to the construction properties of concrete buildings $[12,13]$. When waste fly ash is considered to be used in the cement-based materials, the influence of waste fly ash on the rheological properties of fresh cement paste should be studied systematically. Moreover, it was obtained by some researches that the electrical parameters can be used to reflect the hydration process of cement due to the convenience of electrical methods [14,15]. The hydration process can be reflected by alternating current $(\mathrm{AC})$ electrical resistance, $\mathrm{AC}$ impedance spectrum, and polarization due to the change in conductive pore solution in cement paste [16]. The waste fly ash contains electrically conductive elements, hence the AC impedance spectrum and time history curve of DC (direct current) electrical resistance may be effective to reflect the processes of cement hydration and mechanical strengths [17]. Several researches about the mechanical strengths and microscopic properties of cement-based materials with waste fly ash were reported $[18,19]$. However, little attention has been paid to the multiple sets of electrical parameters of cement paste with waste fly ash.

Aiming at studying the influence of waste fly ash (The waste fly ash was obtained after domestic waste incineration) on the rheological properties of fresh cement paste, the slump flow, and plastic viscosity of fresh cement paste with waste fly ash were investigated in this paper. The following AC electrical resistance, the DC electrical resistance time curves, and the mechanical strengths of hardened specimens were tested to reflect the influence of waste fly ash on the hydration process of cement. The waste fly ash in this study increased from $0 \%$ to $25 \%$ by the mass ratio of total binder materials. The water-binder ratio of all samples in this study was 0.3 . This research will supply new approaches for the application of waste fly ash in the cement-based materials.

\section{Experimental}

\subsection{Raw Materials}

Swan brand Ordinary Portland cement with strength grade of 42.5 MPa provided by Yatai Group Harbin Cement Co., Ltd., Harbin, China, was used in this study. Qiangshi brand polycarboxylate-based water-reducer with water reducing rate of $40 \%$ manufactured by Harbin Qiangshi Concrete Technology Development Co., Ltd., Harbin, China, was used to adjust the rheological properties of fresh cement paste. The solid content of polycarboxylate-based water-reducer was $20 \%$, meanwhile, the alkali content was lower than or equal to $10 \%$.

The solid waste fly ash (WFA) produced by Shanghai Pudong New Area Yuqiao domestic waste incineration plant, Shanghai, China, was used in this experiment. Table 1 shows the composition of raw materials. The water to binder ratio was 0.3 , and the mass ratio of water reducing agent by the total mass of binder materials was $0.3 \%$. Tables 1 and 2 show the chemical composition and the particle size distribution of the cementitious materials. The particle size distribution was obtained by laser particle size analyzer. The testing results were provided by the manufactures. The chemical compositions of WFA was determined by X-ray fluorescence spectrometer. All testing results were provided by the manufactures.

Table 1. Chemical composition of the cementitious materials/\%.

\begin{tabular}{|c|c|c|c|c|c|c|c|c|c|c|c|c|c|c|c|}
\hline Types & $\mathrm{SiO}_{2}$ & $\mathrm{Al}_{2} \mathrm{O}_{3}$ & $\mathrm{Fe}_{2} \mathrm{O}_{3}$ & $\mathrm{MgO}$ & $\mathrm{CaO}$ & $\mathrm{SO}_{3}$ & $\mathrm{~K}_{2} \mathrm{O}$ & $\mathrm{Na}_{2} \mathrm{O}$ & $\mathrm{Ti}_{2} \mathrm{O}$ & $\mathrm{CdO}$ & $\mathrm{Cr}_{2} \mathrm{O}_{3}$ & $\mathrm{PbO}$ & $\mathrm{CuO}$ & $\mathrm{ZnO}$ & $\begin{array}{c}\text { Loss on } \\
\text { Ignition }\end{array}$ \\
\hline WFA & 22.47 & 4.46 & 0.94 & & 20.31 & 9.25 & 5.98 & 4.26 & 10.24 & 0.07 & 0.09 & 0.09 & 0.09 & 0.52 & 21.23 \\
\hline P.O cement & 20.86 & 5.47 & 3.94 & 1.73 & 62.23 & 2.66 & - & - & - & - & - & - & - & - & 3.11 \\
\hline
\end{tabular}


Table 2. Particle passing percentage of the cementitious materials/\%.

\begin{tabular}{cccccccc}
\hline \multirow{2}{*}{ Types } & \multicolumn{7}{c}{ Particle Size/ $\boldsymbol{\mu m}$} \\
\cline { 2 - 8 } & $\mathbf{0 . 3}$ & $\mathbf{0 . 6}$ & $\mathbf{1}$ & $\mathbf{4}$ & $\mathbf{8}$ & $\mathbf{6 4}$ & $\mathbf{3 6 0}$ \\
\hline WFA & 0.13 & 0.46 & 2.15 & 17.21 & 31.34 & 97.52 & 100 \\
P.O cement & 0 & 0.33 & 2.66 & 15.01 & 28.77 & 93.59 & 100 \\
\hline
\end{tabular}

\subsection{Specimen Preparation and Measurement Methods}

The cement and waste fly ash were mixed in the NJ-160A cement paste mixer offered by Wuxi Jian Ding Jian Gong Instrument Factory, Wuxi, China, and stirred at a speed of $140 \mathrm{rpm}$ for $1 \mathrm{~min}$. After this mixing, the uniformly mixed mixture of water and water reducing agent were added to the raw materials and stirred at the speed of $140 \mathrm{rpm}$ for another $1 \mathrm{~min}$. After the mixing was finished, two minutes of stirring with the speed of $285 \mathrm{rpm}$ were provided. After the mixing was finished, a steel cone with a bottom diameter of $60 \mathrm{~mm}$, a top diameter of $36 \mathrm{~mm}$, and a height of $60 \mathrm{~mm}$ was applied in the determination of the slump flow of the prepared fresh paste. Moreover, the plastic viscosity of the paste was determined by the NXS-11B rotating viscometer manufactured by Chengdu Leadership Instruments Co., Ltd., Chengdu, China, with the shear rate of $8 \mathrm{rpm}$. Then, the remaining cement paste was poured to form the specimens with sizes of $50 \mathrm{~mm} \times 50 \mathrm{~mm} \times 50 \mathrm{~mm}$ and $40 \mathrm{~mm} \times 40 \mathrm{~mm} \times 160 \mathrm{~mm}$. Specimens with sizes of $50 \mathrm{~mm} \times 50 \mathrm{~mm} \times 50 \mathrm{~mm}$ and $40 \mathrm{~mm} \times 40 \mathrm{~mm} \times 160 \mathrm{~mm}$ were used for the determination of electrical parameters and mechanical strengths, respectively. The two-electrodes were offered to electrify for the measurement of electrical parameters. The size of electrodes was $45 \mathrm{~mm} \times 65 \mathrm{~mm}$ made by 4 mesh 304 stainless steel meshes. The space between the electrodes was $40 \mathrm{~mm}$. The AC electrical resistance was determined by AC resistance testing instrument named TH2810D LCR digital electric bridge produced by Changzhou Tonghui Co., Ltd., Changzhou, China. The AC power frequency of TH2810D LCR digital electric bridge was $10,000 \mathrm{~Hz}$ with the testing $\mathrm{AC}$ voltage, and the sampling frequencies of $\mathrm{AC}$ electrical resistance measurements were $1 \mathrm{~V}$ and $1 \mathrm{~Hz}$. The measurement of AC electrical resistance is shown in Figure 1. The compressive and flexural strengths of specimens were tested by the YAW-300 microcomputer full-automatic universal with the loading speed of $0.05 \mathrm{kN}$ for the determination of flexural strength and the loading speed of $2.4 \mathrm{kN}$ for the measurement of compressive strength. The measurement of mechanical strengths was carried out according to GB/T 17671-1999 Chinese standard [20]. The DC power with the maximum voltage of $1 \mathrm{~V}$ was provided for the measurement of electrical resistance time history curves. The DC voltage was collected by ADAM 4117 acquisition instrument provided by Nanning Yanhua Electronic Technology Co., Ltd., Nanning, China. The electrical signals were collected per second. The electrical resistance time history curves were determined by reference resistance method. This method can be described as follows:

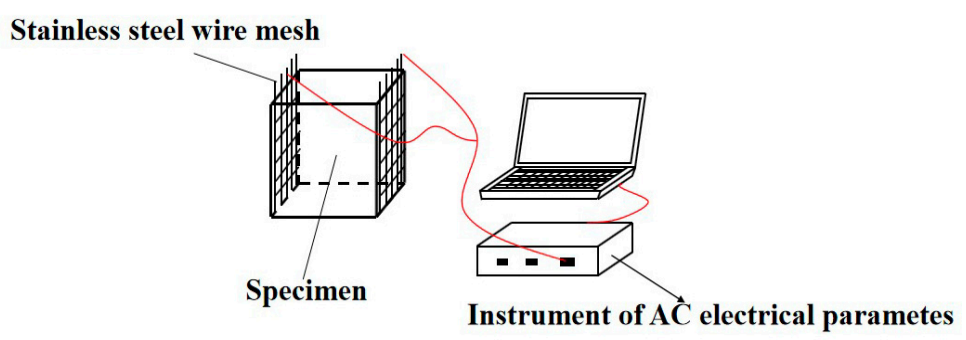

Figure 1. The schematic diagram of AC electrical resistance measurement.

The reference resistor and specimen were series in the circuit and the electrical voltages at the ends of the reference resistor and specimen were collected by ADAM 4117 
acquisition instrument. The DC electrical resistance $\left(R_{d}\right)$ of the specimen can be calculated by Equation (1):

$$
R_{d}=\frac{V_{d} R_{r}}{V_{r}}
$$

where $R_{r}$ is the electrical resistance of the reference resistor, and $V_{d}$ and $V_{r}$ are the electrical voltages of the specimen and the reference resistor, respectively. The determination of DC electrical resistance is shown in Figure 2. In this paper, 3 specimens were applied in the measurement of each mechanical strength, while 6 specimens were used for the determination of each electrical parameter.

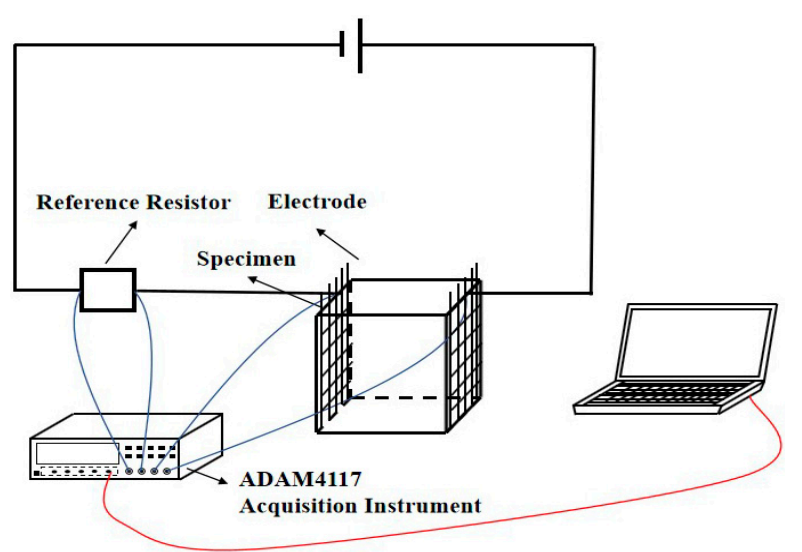

Figure 2. The schematic diagram of DC electrical resistance measurement.

\section{Results and Discussion}

\subsection{Rheological Properties of Fresh Cement Paste}

Figures 3 and 4 show the slump flow and plastic viscosity of fresh cement paste. It can be observed from Figures 3 and 4 that the slump flow decreased and the plastic viscosity increased with the addition of waste fly ash. Moreover, as depicted in these Figures, the curing time of fresh paste led to the reduction of slump flow and the growth of plastic viscosity. When the curing time was $0.5 \mathrm{~h}$, the slump flow of fresh cement paste decreased slowly with the dosages of waste fly ash were $0 \sim 5 \%$ and $20 \sim 25 \%$. However, when the content of waste fly ash varied from $5 \%$ to $20 \%$, the slump flow of fresh cement paste with all curing time decreased obviously. Meanwhile, the similar increasing trend of plastic viscosity occurred with the increasing dosage of waste fly ash and curing time. This was attributed to the fact that the waste fly ash possessed higher specific surface area than that of cement, thus adsorbing more free water and thus decreasing the slump flow and increasing the plastic viscosity of fresh cement paste. Additionally, the increasing testing time results in increased hydration and compactness, thus decreasing the fluidity and increasing the viscosity [21,22]. Comparing the rheological properties of cement paste with rice husk ash, the slump flow of fresh cement paste decreased with the increasing dosages of rice husk ash and waste fly ash. This was attributed to the fact that the particle diameters of rice husk ash and waste fly ash were smaller than that of cement particles, thus resulting in increasing the surface area of cementitious material leading eventually to adsorbing the free water of fresh cement paste and decreasing the slump flow. Moreover, the fresh cement paste with rice husk ash shows a lower slump flow than that of fresh cement paste with waste fly ash due to its higher superficial area $[23,24]$. 


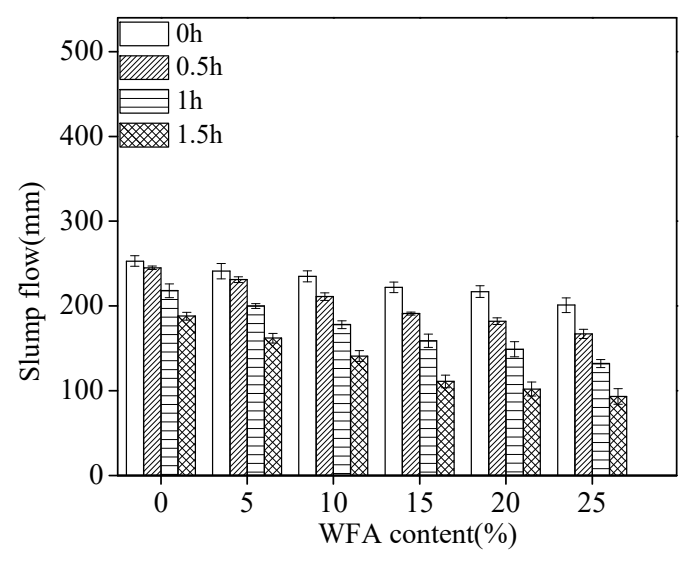

(a)

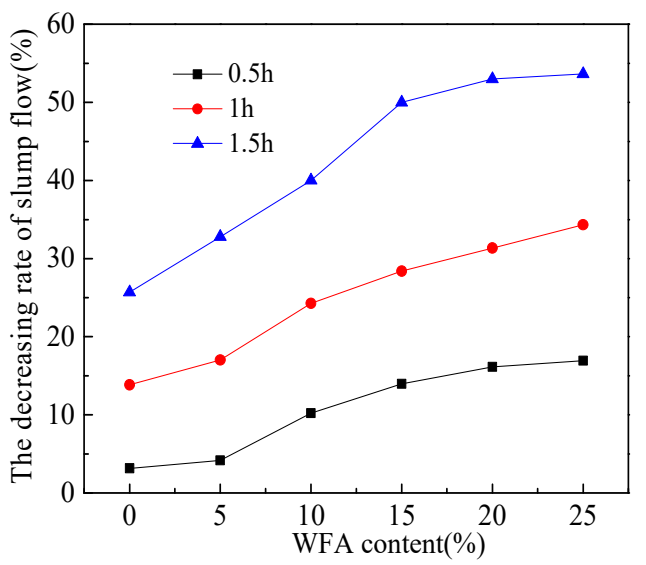

(b)

Figure 3. The slump flow of fresh cement paste with different dosages of waste fly ash. (a) The slump flow of fresh paste, (b) the decreasing rate of slump flow.

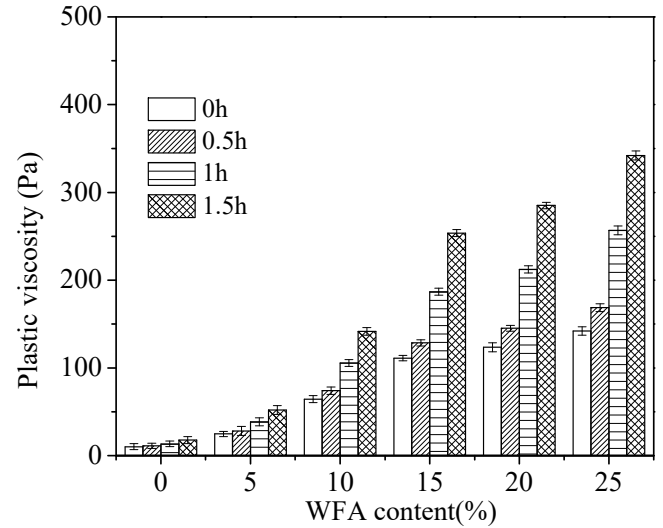

(a)

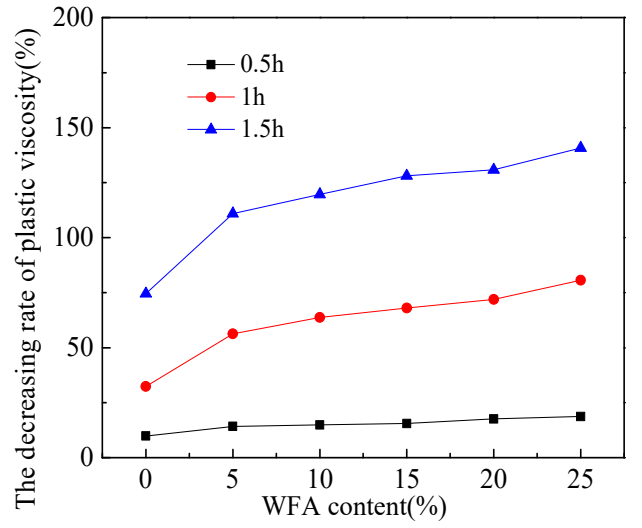

(b)

Figure 4. The plastic viscosity of fresh cement paste with different dosages of waste fly ash. (a) The plastic viscosity of fresh paste, (b) the decreasing rate of plastic viscosity.

\subsection{Electrical Parameters of Cement Paste}

Figure 5 shows the AC electrical resistance of cement paste with the curing time increasing from $0.5 \mathrm{~h}$ to $28 \mathrm{~d}$. As illustrated in Figure 5, the AC electrical resistance increased in the form of a quadratic function with the cuing age due to the fact that the increased hydration degree consumed free water in the pore solution, leading to decreasing the electrical conduction and increasing the electrical resistance of specimens. Additionally, the increasing dosages of waste fly ash led to decreasing the AC electrical resistance. This was attributed to the fact that the waste fly ash contains higher amount of metal elements which could provide a large number of conductive electrons, thus improving the electrical conduction and decreasing the electrical resistance $[25,26]$. Table 3 shows the fitting results of the relationship between the electrical resistance and the curing time. It can be obtained from Table 3 that the electrical resistance and curing time conforms to a quadratic function. The fitting degrees of all fitting curves are higher than 0.97, indicating the high degree of fitting equations. 


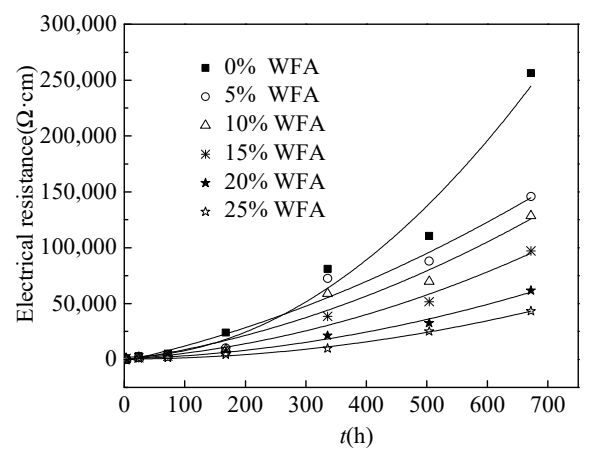

Figure 5. The AC electrical resistance of cement paste with different dosages of waste fly ash.

Table 3. Mixing mass proportion of cement paste.

\begin{tabular}{cccc}
\hline Cement & Water & WFA/\% & Water Reducing Agent $/ \%$ \\
\hline 100 & 30 & 0 & 0.3 \\
95 & 30 & 5 & 0.3 \\
90 & 30 & 10 & 0.3 \\
85 & 30 & 15 & 0.3 \\
80 & 30 & 20 & 0.3 \\
75 & 30 & 25 & 0.3 \\
\hline
\end{tabular}

Figure 6 shows the variation rate of DC electrical resistance of cement paste cured for $1 \mathrm{~d}, 3 \mathrm{~d}, 7 \mathrm{~d}$, and $28 \mathrm{~d}$. It can be obtained from Figure 6 that the DC electrical resistance increased with the increasing testing time due to the electric polarization, thus resulting in the electrical resistance increasing with the conducting time [27]. Moreover, the addition of waste fly ash and the increasing curing time demonstrated the increasing roles in the variation rate of DC electrical resistance.

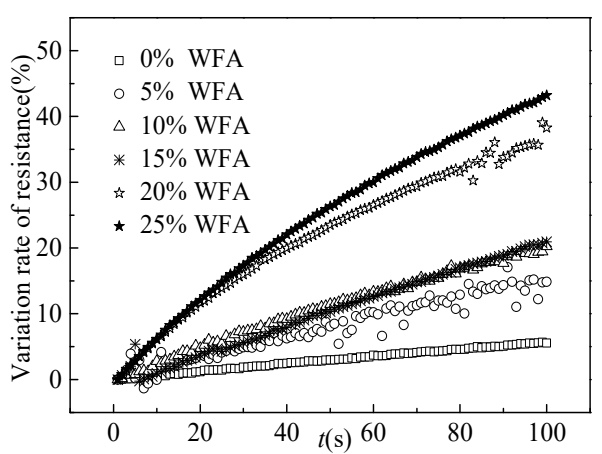

(a)

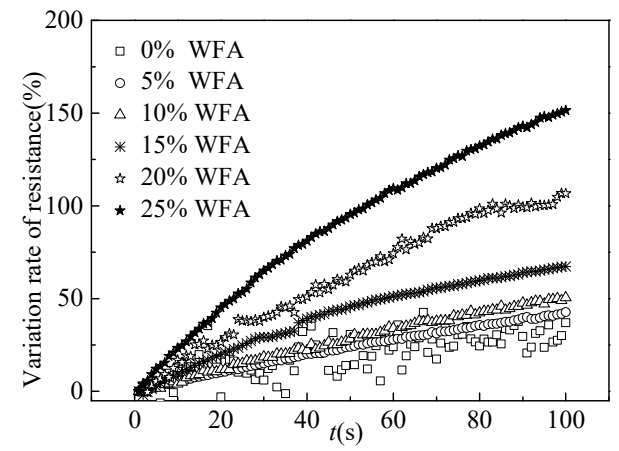

(c)

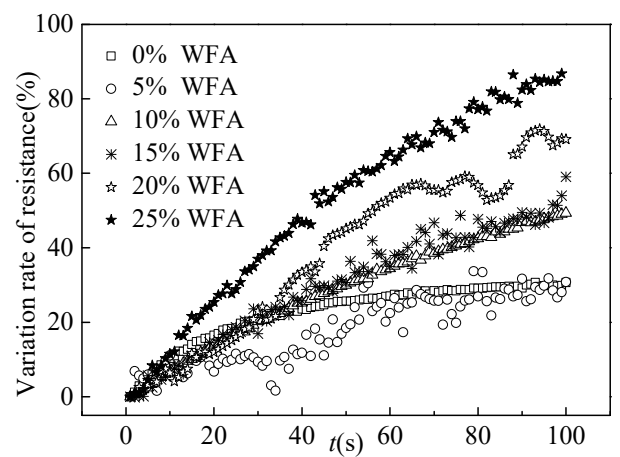

(b)

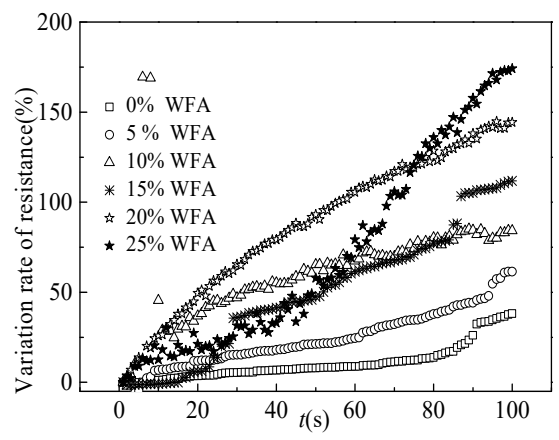

(d)

Figure 6. DC electrical resistance-time curves of cement paste with different dosage of waste fly ash. (a) $1 \mathrm{~d}$, (b) $3 \mathrm{~d}$, (c) $7 \mathrm{~d}$, (d) $28 \mathrm{~d}$. 
Figure 7 shows electrochemical impedance spectroscopy curves of specimens cured for $1 \mathrm{~d}$ and $28 \mathrm{~d}$. The extreme points of all curves decreased with the increasing dosages of waste fly ash, indicating that the addition of waste fly ash could improve the electrical conduction and lead to decreasing the electrical resistance of specimens due to the increased conductive particles by the metallic elements, thus improving the electrical conductivity and decreasing the electrical resistance. Moreover, the extreme points of all curves increased with the increased curing ages due to the improved hydration degree, thus decreasing the free ions and the electrical resistance $[28,29]$.

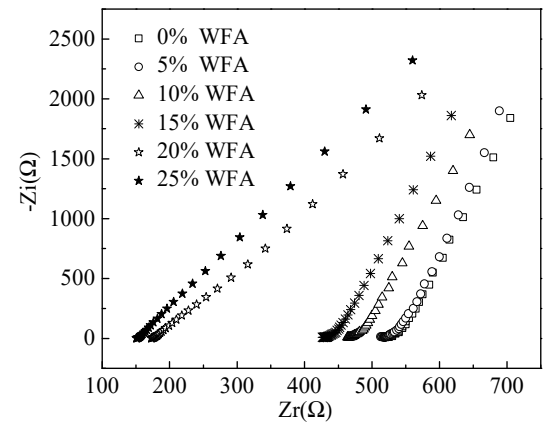

(a)

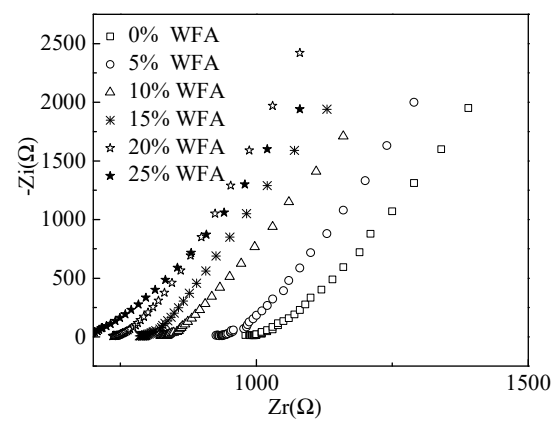

(b)

Figure 7. EIS curves of cement paste with different dosages of waste fly ash. (a) $1 \mathrm{~d}$, (b) $28 \mathrm{~d}$.

Figure 8 shows the equivalent circuit diagram of specimens. The circular section can be represented by the parallel of resistance and capacitance elements. The initial resistance $\left(R_{S}\right)$ corresponds to the contact resistance between specimen and electrodes. Then, the following series of connected electrical components represented the shunt-wound resistance $\left(R_{1}\right)$ and electrical capacitance $\left(C_{1}\right)$ of the pore solution. A conductive pathway was formed by the pore solution in the cement matrix. The Chi-squared of the equivalent circuit diagram was less than or equal to $1.451 \times 10^{-4}$, ensuring the validity of the equivalent circuits.
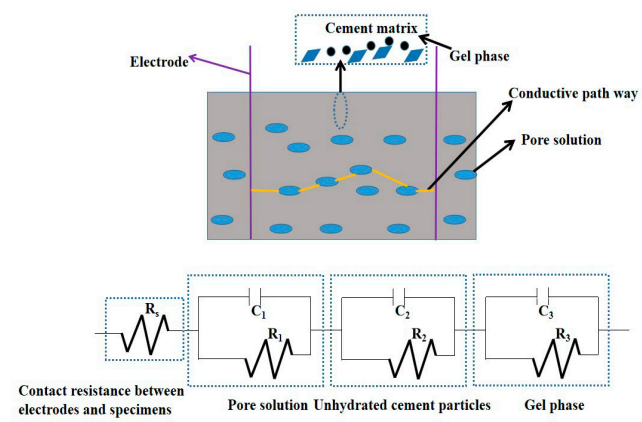

Figure 8. Corresponding equivalent circuits of cement paste with different dosages of waste fly ash.

\subsection{Mechanical Strengths}

Figure 9 shows the flexural and compressive strengths of cement paste cured for $1 \mathrm{~d}$, $3 \mathrm{~d}, 7 \mathrm{~d}$, and $28 \mathrm{~d}$. Table 4 shows the values of the fitting results of the mechanical strengths and the mass ratio. Figure 10 shows the increasing rate of the mechanical strengths compared to the mechanical strengths with $0 \%$ waste fly ash. Table 5 shows the fitting results of mechanical strength and mass ratio $(\omega)$ of WFA. As shown in Figures 9 and 10, the relationship between mechanical strengths and the mass ratio of waste fly ash increased in the form of a quadratic function. The curing age led to improving the mechanical strengths of cement paste. The increasing rate of mechanical strengths by the addition of waste fly ash decreased by the curing age and firstly increased and then decreased with the increasing mass ratio of waste fly ash. When the mass ratio of waste fly ash was $15 \%$, the increasing effect is the most obvious. This was attributed to the fact that the active 
substance of waste fly ash could improve the hydration process of cement, especially in the early hydration state [30,31]. Therefore, the mechanical strengths were increased by the addition of waste fly ash, especially in earlier curing ages. It can be obtained from Table 4 that the fitting degree of all curves are higher than or equal to 0.96 , ensuring the rationality of fitting equations.

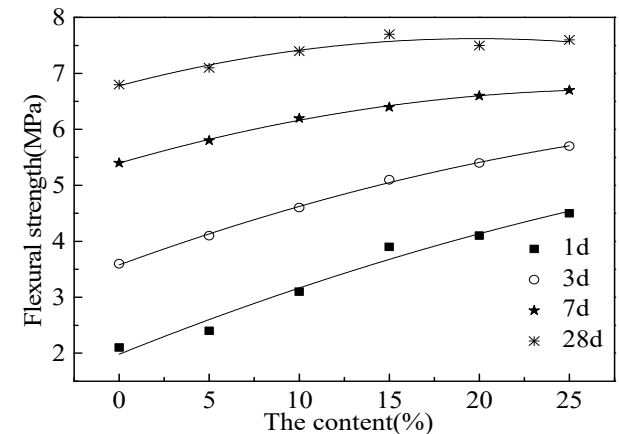

(a)

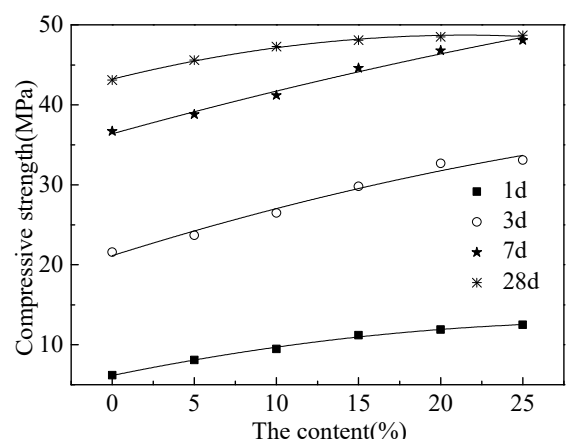

(b)

Figure 9. The mechanical strengths of cement paste with different dosage of waste fly ash. (a) Flexural strength, (b) Compressive strength.

Table 4. The fitting results of electrical resistance and the curing time.

\begin{tabular}{cccccc}
\hline Equation & WFA Content/\% & $\mathbf{a}$ & $\mathbf{b}$ & c & R2 \\
\hline & 0 & $5.27 \times 10^{-1}$ & 7.08 & 1945.46 & 0.97 \\
$R=a t^{2}+b t+c$ & 5 & $1.44 \times 10^{-1}$ & 120.66 & -1462.79 & 0.97 \\
& 10 & $1.65 \times 10^{-1}$ & 77.50 & -584.65 & 0.97 \\
& 15 & $1.51 \times 10^{-1}$ & 40.00 & 45.26 & 0.98 \\
& 20 & $1.06 \times 10^{-1}$ & 18.17 & 368.96 & 0.99 \\
& 25 & $9.3 \times 10^{-2}$ & 1.20 & 402.99 & 0.99 \\
\hline
\end{tabular}

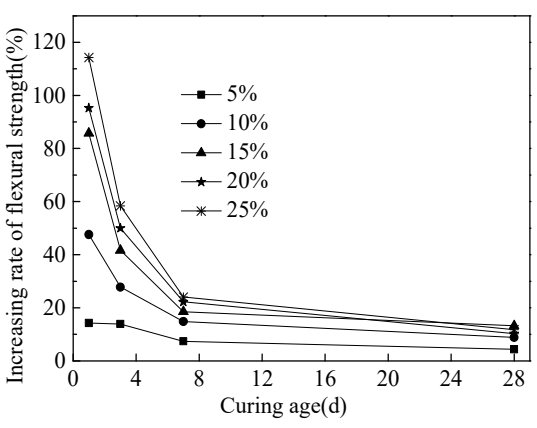

(a)

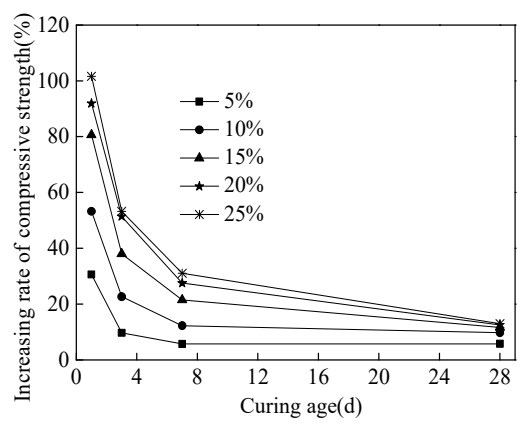

(b)

Figure 10. The increasing rate of mechanical strengths: (a) The increasing rate of flexural strength; (b) The increasing rate of compressive strength. 
Table 5. The fitting results of mechanical strength and mass ratio $(\omega)$ of WFA.

\begin{tabular}{ccccccc}
\hline $\begin{array}{c}\text { Mechanical } \\
\text { Strengths }\end{array}$ & Equation & Curing Age/d & $\boldsymbol{a}$ & $\boldsymbol{b}$ & $\boldsymbol{c}$ & $\boldsymbol{R}^{\mathbf{2}}$ \\
\hline \multirow{2}{*}{$\begin{array}{c}\text { Flexural } \\
\text { strength }\end{array}$} & $-f_{t}=$ & 1 & $-1.07 \times 10^{-3}$ & 0.13 & 1.98 & 0.96 \\
& $a \omega^{2}+a \omega+c$ & 3 & $-1.29 \times 10^{-3}$ & 0.12 & 3.58 & 0.99 \\
& - & 7 & $-1.64 \times 10^{-3}$ & 0.09 & 5.40 & 0.99 \\
& - & 28 & $-2.14 \times 10^{-3}$ & 0.09 & 6.78 & 0.99 \\
\hline \multirow{2}{*}{$\begin{array}{c}\text { Compressive } \\
\text { strength }\end{array}$} & - & 1 & $-6.64 \times 10^{-3}$ & 0.42 & 6.16 & 0.99 \\
& $f^{2}+a \omega+c$ & 3 & $-5.79 \times 10^{-3}$ & 0.65 & 21.15 & 0.97 \\
& - & 7 & $-3.43 \times 10^{-3}$ & 0.57 & 36.39 & 0.98 \\
& - & 28 & $-1.19 \times 10^{-2}$ & 0.51 & 43.21 & 0.99 \\
\hline
\end{tabular}

\section{Conclusions}

In this study, the influence of waste fly ash (WFA) on the rheological properties, the electrical properties and the mechanical strengths were investigated and the conclusions were summarized as follows:

The addition of waste fly ash and the testing time led to decreasing the slump flow and increasing the plastic viscosity of fresh cement paste.

The relationship between the alternating current's (AC) electrical resistance and curing time was the positive correlation quadratic function. Meanwhile, the addition of WFA could improve the electrical conduction of cement paste. The variation rate of direct current (DC) electrical resistance during the testing time increased with the increasing dosages of WFA and the curing age. The equivalent circuits consisted of three resistor elements and three capacitance elements. Resistors or capacitances were in series connection. Between each capacitance and resistor, the parallel circuit was more reasonable.

The relationship between the mechanical strength and the mass ratio of waste fly ash increased in the form of a quadratic function. The curing age led to improving the mechanical strengths of cement paste. The increasing rate of mechanical strength by the addition of waste fly ash decreased by the curing age and firstly increased and then decreased with the mass ratio of waste fly ash. When the mass ratio of waste fly ash was $15 \%$, the increasing effect is the most obvious.

It can be obtained from this paper that the addition of WFA could effectively improve the mechanical strengths of cement paste. However, WFA led to decreasing the fluidity of fresh cement paste. Moreover, the electrical parameters could be applied in reflecting the hydration process of cement-based materials with WFA. Furthermore, the research of the in-depth mechanism of the electrical and mechanical properties is limited and will be further studied in the future.

Author Contributions: Conceptualization, H.W. and L.C.; methodology, L.C.; software, L.C..; validation, H.W. and L.C.; formal analysis, H.W.; investigation, L.C.; resources, H.W.; data curation, L.C.; writing-original draft preparation, H.W.; writing-review and editing, H.W.; visualization, L.C.; supervision, H.W.; project administration, L.C.; funding acquisition, H.W. All authors have read and agreed to the published version of the manuscript.

Funding: This work is sponsored by the Zhejiang Provincial Natural Science Foundation [No. Y22E081344] and the National Natural Science Foundation of China [No. 51808300 and No. 52178195].

Institutional Review Board Statement: Not applicable.

Informed Consent Statement: Not applicable.

Data Availability Statement: The data used to support the findings of this study are available from the corresponding author upon request. 
Conflicts of Interest: The authors declare that there are no conflict of interest regarding the publication of this paper.

\section{References}

1. Avila-López, U.; Almanza-Robles, J.M.; Escalante-García, J. Investigation of novel waste glass and limestone binders using statistical methods. Constr. Build. Mater. 2015, 82, 296-303. [CrossRef]

2. Chen, L.; Wang, Y.; Wang, L.; Zhang, Y.; Li, J.; Tong, L.; Hu, Q.; Dai, J.-G.; Tsang, D.C.W. Stabilisation/solidification of municipal solid waste incineration fly ash by phosphate-enhanced calcium aluminate cement. J. Hazard. Mater. 2021, 408, 124404. [CrossRef] [PubMed]

3. Diaz-Loya, E.; Allouche, E.; Eklund, E.; Joshi, A.R.; Kupwade-Patil, K. Toxicity mitigation and solidification of municipal solid waste incinerator fly ash using alkaline activated coal ash. Waste Manag. 2012, 32, 1521-1527. [CrossRef] [PubMed]

4. Hrvoje, M.; Jaromír, K.; Vujanović, M.; Urbaniec, K.; Duić, N. Reducing greenhouse gasses emissions by fostering the deployment of alternative raw materials and energy sources in the cleaner cement manufacturing process. J. Clean. Prod. 2016, 136, 119-132.

5. Li, Y.; Li, X.; Tan, Y. Effect of aging on fatigue performance of cement emulsified asphalt repair material. Constr. Build. Mater. 2021, 292, 123417. [CrossRef]

6. Ren, J.; Hu, L.; Dong, Z.; Tang, L.; Xing, F.; Liu, J. Effect of silica fume on the mechanical property and hydration characteristic of alkali-activated municipal solid waste incinerator (MSWI) fly ash. J. Clean. Prod. 2021, 295, 126317. [CrossRef]

7. Tian, X.; Rao, F.; Morales-Estrella, R.; Song, S. Effects of aluminum dosage on gel formation and heavy metal immobilization in alkali-activated municipal solid waste incineration fly ash. Energy Fuels 2020, 34, 4727-4733. [CrossRef]

8. Zhang, Y.; Wang, L.; Chen, L.; Ma, B.; Zhang, Y.; Ni, W.; Tsang, D. Treatment of municipal solid waste incineration fly ash: State-of-the-art technologies and future perspectives. J. Hazard. Mater. 2021, 411, 125132. [CrossRef] [PubMed]

9. Rehman, A.; Lee, S.; Kim, J. Use of municipal solid waste incineration ash in 3D printable concrete. Process. Saf. Environ. Prot. 2020, 142, 219-228. [CrossRef]

10. Du, B.; Li, J.; Fang, J.; Liu, J. Comparison of long-term stability under natural ageing between cement solidified and chelatorstabilised MSWI fly ash. Environ. Pollut. 2019, 250, 68-78. [CrossRef]

11. Alderete, N.; Joseph, A.; Van den Heede, P.; Matthys, S.; De Belie, N. Effective and sustainable use of municipal solid waste incineration bottom ash in concrete regarding strength and durability. Resour. Conserv. Recycl. 2021, 167, 105356. [CrossRef]

12. Yahia, A.; Tanimura, M. Rheology of belite-cement-effect of w/c and high-range water-reducer type. Constr. Build. Mater. 2015, 88, 169-174. [CrossRef]

13. Ma, S.; Qian, Y.; Kaishima, S. Experimental and modeling study on the non-linear structural build-up of fresh cement pastes incorporating viscosity modifying admixtures. Cem. Concr. Res. 2018, 108, 1-9. [CrossRef]

14. Xu, D.; Huang, S.; Qin, L. Monitoring of cement hydration reaction process based on ultrasonic technique of piezoelectric composite transducer. Constr. Build. Mater. 2012, 35, 220-226.

15. Wang, H.; Zhang, A.; Zhang, L.; Wang, Q.; Han, Y.; Liu, J.; Gao, X.; Shi, F.; Lin, X.; Feng, L. Hydration process of rice husk ash cement paste and the following corrosion resistance of embedded steel bar. J. Cent. South Univ. 2020, 11, 3464-3476. [CrossRef]

16. Wang, H.; Hu, L.; Cao, P.; Luo, B.; Tang, J.; Shi, F.; Yu, J.; Li, H.; Jin, K. The Application of Electrical Parameters to Reflect the Hydration Process of Cement Paste with Rice Husk Ash. Materials 2019, 12, 2815. [CrossRef] [PubMed]

17. Cioffi, R.; Colangelo, F.; Montagnaro, F.; Santoro, L. Manufacture of artificial aggregate using MSWI bottom ash. Waste Manag. 2011, 31, 281-288. [CrossRef] [PubMed]

18. Ulubeyli, G.; Artir, R. Properties of Hardened Concrete Produced by Waste Marble Powder, World Conference on Technology. Procedia-Soc. Behav. Sci. 2015, 195, 2181-2190.

19. Liu, L.; Hu, L.; Tang, L.; Ren, J. Utilisation of municipal solid waste incinerator (MSWI) fly ash with metakaolin for preparation of alkali-activated cementitious material. J. Hazard. Mater. 2021, 402, 123451. [CrossRef]

20. Supervision, T. Method of Testing Cements-Determination of Strength; GB/T 17671-1999; The State Bureau of Quality and Technical Supervision: Beijing, China, 1999.

21. Wang, H.; Du, T.; Zhang, A.; Cao, P.; Zhang, L.; Gao, X.; Liu, J.; Shi, F.; He, Z. Relationship between electrical resistance and rheological parameters of fresh cement slurry. Constr. Build. Mater. 2020, 256, 119479. [CrossRef]

22. Jiao, D.; Shi, C.; Yuan, Q.; An, X.; Liu, Y.; Li, H. Effect of constituents on rheological properties of fresh concrete-A review. Cem. Concr. Compos. 2017, 83, 146-159. [CrossRef]

23. Kleib, J.; Aouad, G.; Abriak, N.; Benzerzour, M. Production of Portland cement clinker from French Municipal Solid Waste Incineration Bottom Ash. Case Stud. Constr. Mater. 2021, 15, e00629. [CrossRef]

24. Lee, K.; Matlina Mohtar, A.; Zainudin, N.; Bhatia, S.; Mohamed, A.R. Optimum conditions for preparation of flue gas desulfurization absorbent from rice husk ash. Fuel 2005, 84, 143-151. [CrossRef]

25. Das, S.; Lee, S.H.; Kumar, P.; Kim, K.-H.; Lee, S.S.; Bhattacharya, S.S. Solid waste management: Scope and the challenge of sustainability. J. Clean. Prod. 2019, 228, 658-678. [CrossRef]

26. Huang, G.; Yuan, L.; Ji, Y.; Liu, B.; Xu, Z. Cooperative action and compatibility between Portland cement and MSWI bottom ash alkali-activated double gel system materials. Constr. Build. Mater. 2019, 209, 445-453. [CrossRef]

27. Wang, H.; Shen, J.; Liu, J. Influence of carbon nanofiber content and sodium chloride solution on the stability of resistance and the following self-sensing performance of carbon nanofiber cement paste. Case Stud. Constr. Mater. 2019, 11, e00247. [CrossRef] 
28. Wang, H.; Gao, X.; Liu, J. Effects of salt freeze-thaw cycles and cyclic loading on the piezoresistive properties of carbon nano-fibers mortar. Constr. Build. Mater. 2018, 177, 192-201. [CrossRef]

29. Wang, H.; Jin, K.; Zhang, A.; Zhang, L.; Han, Y.; Liu, J.; Shi, F.; Feng, L. External erosion of sodium chloride on the degradation of self-sensing and mechanical properties of aligned stainless steel fiber reinforced reactive powder concrete. Constr. Build. Mater. 2021, 287, 123028. [CrossRef]

30. Ferraro, A.; Farina, I.; Race, M.; Colangelo, F.; Fabbricino, M. Pre-treatments of MSWI fly-ashes: A comprehensive review to determine optimalconditions for their reuse and/or environmentally sustainable disposal. Rev. Environ. Sci. Biotechnol. 2019, 18, 453-471. [CrossRef]

31. Li, X.; Chen, Q.; Zhou, Y.; Tyrer, M.; Yu, Y. Stabilization of heavy metals in MSWI fly ash using silica fume. Waste Manag. 2014, 34, 2494-2504. [CrossRef] [PubMed] 